\title{
La tradición religiosa al servicio del folklorismo
}

El término «folklorismo», al margen de su significado más genérico, alusivo a la tarea propia de los folkloristas, se utiliza también en antropología para designar aquel conjunto de ideas, valores, actitudes y procederes que hacen referencia al uso social que, de manera consciente, se hace hoy día del folklore ${ }^{1}$. El concepto de "folklorismo" presupone la existencia de una conciencia de tradición, su valoración positiva a priori y una intencionalidad - generalmente de índole estética, comercial o ideológica- en cuanto al uso que se quiere otorgar a esta tradición. La relevancia de esta categoría para entender buena parte de las manifestaciones del folklore en nuestra actual sociedad occidental es evidente. Desde que la "tradición " -especialmente la rural - ha empezado a ser vista desde una perspectiva urbana como *folklore, ha recibido un valor social adicional que anteriormente desconocía. Ello ha comportado una cierta alteración, tanto en su dinámica interna evolutiva, como en sus formas, contenidos y funciones. Gracias al folklorismo se han mantenido numerosas manifestaciones culturales de corte preindustrial que el desarrollo de nuestra sociedad tendía a hacer desaparecer. Pero evidentemente, lo conservado no es nunca lo mismo que se pretendía conservar. Aunque a menudo nos engañemos a nosotros mismos, la canción tradicional, por ejemplo, que podamos escuchar hoy día cantada por un amante de las tradiciones no será nunca lo mismo que lo que era cuando se la rescató de su contexto original. Lo que antes se difundía por transmisión oral y, por tanto, estaba sujeto a la variabilidad que le imponía la diacronía, deviene ahora estático mediante su fijación con la notación gráfica o la grabación sonora del recopilador. Lo que antes era una canción cotidiana entre muchas, que nadie se hubiese atrevido a mostrar más allá del umbral de la alcoba, de la taberna o de la parcela del terruño donde se araba con el macho, pasa ahora a ser "patrimonio étnico" y digna, por tanto, de ser ofrecido en los escenarios. Las formas de este folklore rescatado se adaptarán a los gustos

1 Sobre la problemática del folklorismo véase: Josep MARTf I PÉREZ, -El Folklorismo. Análisis de una tradición "Prêt-à-porter", Anuario Musical, 45 (1990), pp. 317-352; id., "La dinàmica del folklorisme musical en les societats occidentalsw, Iñaki DOMíNGUEZ, Arturo RODRfGUEZ MORATÓ (eds.), Arte, cultura y sociedad (Barcelona, 1992), pp. 166-177. 
y necesidades del nuevo público, se le darán nuevos usos y funciones y sobre todo habrá recibido una significación adicional que no tenía antes: la representatividad para un grupo humano que se define a sí mismo mediante criterios de etnicidad.

Dado que el mundo de la vida tradicional está profusamente impregnado de formas y contenidos procedentes del ámbito religioso, no debe extrañarnos que la práctica folklorística de nuestra sociedad recurracon notable insistencia a las manifestaciones culturales colectivas surgidas de la religiosidad popular. De esta manera, el ámbito semánticode muchas celebraciones o manifestaciones propias de las devociones populares cuenta con un nuevo componente: junto al sentimientode religiosidad se halla también el culto a la tradición que representael folklorismo. En ocasiones, en aquellos casos de folklorismo más evidentes, la componente semántica de tipo folklorista llega a desbancar completamente el antiguo significado religioso de la fiesta. Aunque en muchas de estas fiestas se conserve una determinada simbología religiosa, ésta pierde su significado real para pasar a ser un mero aspecto formal, cuyo valor ya no es el que se le asignaba en el pasado, sino que radicará en el hecho de que representa la "tradición", que es al fin y al cabo a lo que, a través del acto folklorístico, se rinde homenaje. Dicho de otra manera, el contenido de la manifestación en sí puede continuar siendo religioso, pero su proyección semántica en la colectividad ya no es religiosa.

Las celebraciones propias de Semana Santa cuentan con una gran riqueza ritual, fuertemente marcada por peculiaridades locales que constituyen un magnífico terreno abonado para el folklorismo y muestran por ello claramente la dinámica del fenómeno. Pensemos, por ejemplo, en la representación de la Pasión que cada año se celebra en la localidad ampurdanesa de Verges, en la cual se incluye el conocido cuadro de la danza de la muerte ${ }^{2}$. En este caso, el sentido estricto de la celebración es indudablemente de tipo religioso. Hoy día, no obstante, la mayoría de los participantes, de manera especial los más jóvenes, separan claramente este conjunto de actos de su Semana Santa de la religiosidad. Ellos hablan de una representación que pertenece exclusivamente a su colectividad, en la cual se ejecuta una corta danza de origen medieval que, de acuerdo con sus propias palabras, "ho portem a la sang" ${ }^{3}$ y resulta por tanto inimitable por parte de otras poblaciones vecinas que en décadas anteriores han intentado adoptarla sin éxito. La población de esta pequeña localidad del Bajo Ampurdán sabe que, gracias a este pequeño

2 Sobre esta danza véase, por ejemplo: Dionisio PRECIADO, Folklore español: música, danza y ballet (Madrid, 1969), pp. 185-186; M. Carmen GARCí MATOS -La Danza de la Muerte y su supervivencia en la tradición folklórica hispana., Revista de Musicología, VIII, 2 (1985), pp. 257-272.

3 "Lo llevamos en la sangre. Según trabajo de campo realizado en 1991. 
cuadro de la danza de la muerte, el nombre de Verges es conocido por muchos catalanes y visitantes de otras procedencias. Si antes, los actos se representaban sobre todo para la propia colectividad, hoy, el día de Jueves Santo, poniéndose en marcha un complejo proceso organizativo en el cual participa toda la población, el municipio se moviliza para dar la bienvenida a varios miles de visitantes, se edita un programa en varias lenguas y se cobra para ver el espectáculo de la misma manera como lo haría cualquier teatro comercial. Nadie duda en calificar de areligioso" el contenido de la representación, pero ésta, bien poco tiene ya que ver con el profundo sentido cristiano que la inspiraría en sus orígenes. Ia función cultural y didácticoreligiosa que podía poseer esta manifestación va perdiendo terreno progresivamente, para ser sustituida por otras funciones de naturaleza lúdica, ideológica o comercial.

Esta metamorfosis en los aspectos semánticos y funcionales de la celebración religiosa a través del folklorismo representa, de hecho, un verdadero "reciclaje" social de unos usos y costumbres, que permite su mantenimiento y supervivencia formal. En l'Alguer, ciudad sarda de lengua catalana, la Semana Santa constituye hoy día la manifestación cultural del ciclo anual más importante de la población ${ }^{4}$. Los actos de la Semana Santa se inician con la celebración del Domingo de Ramos que incluye una procesión, preámbulo de las diversas que a lo largo de estas fechas se realizan en l'Alguer. El punto culminante de la Semana Santa algueresa lo constituye el Viernes Santo. En este día se realiza la procesión más importante que inicia su recorrido después de haberse efectuado en la catedral el "Desclavament, representación dramática del descendimiento de Jesucristo de la cruz, que en l'Alguer se conserva desde hace siglos como herencia de aquellas representaciones religiosas de la Edad Media y, sobre todo, del tiempo de la Contrarreforma. Con el declive de la vida de corte tradicional que esta ciudad sarda empezó a experimentar de manera muy acusada después de la Segunda Guerra Mundial, este conjunto de manifestaciones culturales de tipo religioso se iban sumiendo cada vez más en un abúlico postergamiento hasta que hace algo más de dos décadas sufrieron una importante revitalización, pero no por razones religiosas, sino por motivos de índole folklorística: por una parte, debido a la concienciación de la población de la existencia de un mundo tradicional en vías de desaparición que valía la pena conservar y que era precisamente en los actos de su Semana Santa donde encontraba una de sus mejores expresiones; por otra parte, debido a las grandes posibilidades que ofrecía para la captación turística. Siendo l'Alguer actualmente uno de los

4 Cfr. Josep MARTI I PÉREZ, L'Alguer. Kulturanthropologische Monographie einer sardischen Stadt (Berlin, 1986), pp. 289-295. 
núcleos turísticos más importantes de la costa sarda, la potenciación de su Semana Santa le ha permitido adelantar en el calendario anual el inicio de la estación turística que tantos beneficios económicos le acarrea. Los viejos alguereses se quejan del decreciente espíritu religioso en estos días de Semana Santa. La ciudad se halla literalmente invadida de turistas, muchos de ellos procedentes del ámbito catalanoparlante español, que llegan a l'Alguer en vuelos "charter" fletados especialmente para la ocasión. Estas circunstancias hacen que las calles por donde desfilan las diversas procesiones de la Semana Santa ofrezcan un ambiente festivo totalmente desconocido décadas atrás. El folklorista Joan Amades, hablándonos de la dramática escena del -Desclavament. del Viernes Santo alguerés, escribió hace ya algunas décadas: "...molta gent plora compungidan ${ }^{5}$. Esto ha pasado definitivamente a la historia. Hoy día, la catedral se llena de visitantes, y no son precisamente los gemidos piadosos los que acompañan el descendimiento de la cruz del -Crist de la Misericòrdia" alguerés, sino los frenéticos "clics" de las cámaras fotográficas y los mal disimulados murmullos de un público impaciente. Los signos de duelo propios de los alguereses para el Viernes Santo prácticamente ya han desaparecido. La costumbre de ayunar tomando como único alimento del día la alla podrida — - sencillo plato de verduras- sólo se halla en la memoria de los más viejos; de la prohibición de cantar o escuchar música ya nadie se acuerda; y los rigurosos trajes de luto con los que se participaba en las procesiones son cada vez más insólitos. Se puede entender mejor el sentido de la Semana Santa para esta localidad sarda teniendo en cuenta que hoy día, parte de la financiación de los gastos que acarrea su celebración van a cargo de la Cámara de turismo de la localidad.

Las implicaciones económicas de estas manifestaciones de raíz tradicional son tan evidentes que no nos ha de extrañar que las instituciones locales de muchas comarcas, hoy todavía "anónimas" y con problemas de subsistencia, vean en determinados elementos de su folklore un posible factor de atracción turística para la zona.

Desde hace algunos años, se habla en Aragón de la Ruta del tambor y del bombo ${ }^{6}$. La palabra *ruta ya representa de por sí una invitación turística. Actualmente, son diversas las poblaciones que constituyen este recorrido turístico, agrupadas alrededor de una asociación que precisamente tiene la finalidad de explotarla '. La denominación dada a la ruta, formada por estos

\footnotetext{
5 ...mucha gente llora compungida. Joan AMADES, Costumari català (Barcelona, 1953), vol. II, p. 805.

6 Los datos empíricos contenidos en esta referencia a la Semana Santa del Bajo Aragón proceden de un trabajo de campo realizado en 1992.

7 Estas poblaciones son Albalate del Arzobispo, Alcañiz, Alcorisa, Andorra, Calanda, Hijar, La Puebla de Hijar, Samper de Calanda y Urrea de Gaén.
} 


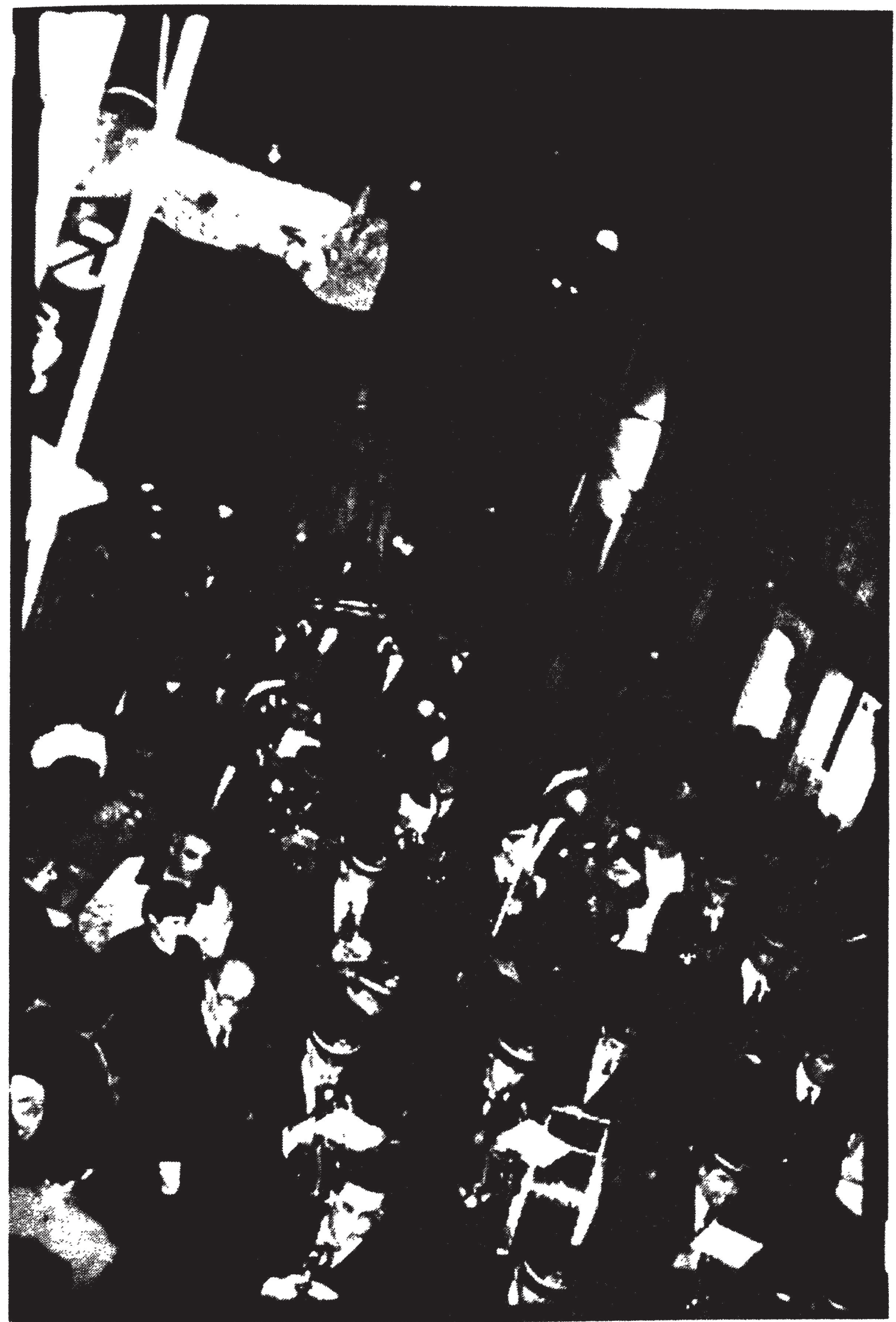

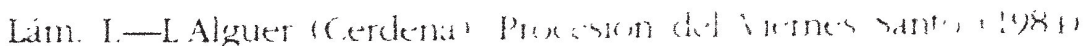




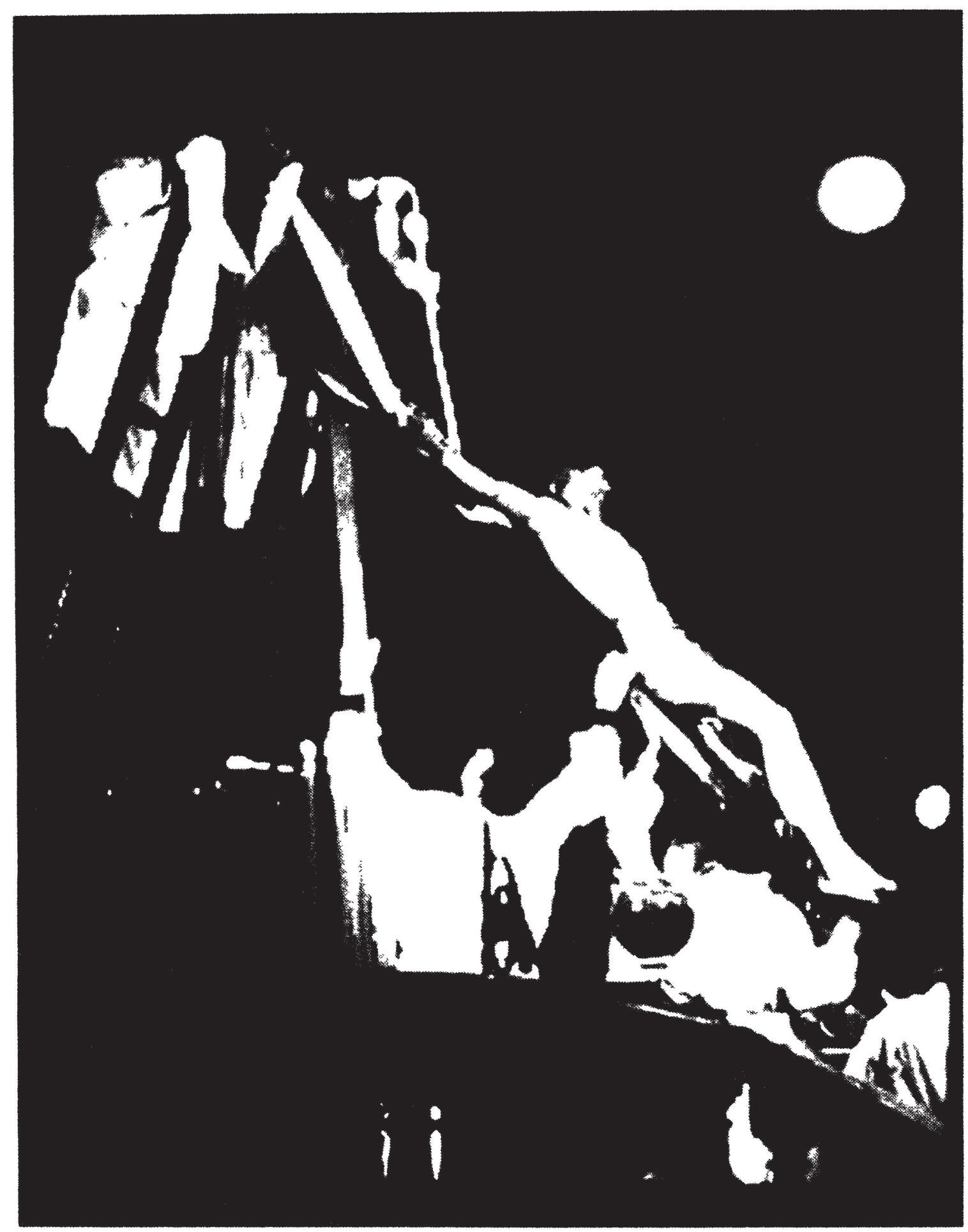

Lam II-LAlguer (Cerdeña): Escena del Descendimiento durante la ceremonia del "Desclavament" del Viemes Santo (1984) 
pueblos, proviene del uso masivo que se hace del bombo y del tambor en los actos propios de Semana Santa. En algunos de los pueblos de la ruta se trata de una costumbre de más de cien años, en otros, no obstante, el fenómeno es de un origen mucho más reciente. No tan solo se fomenta e intenta explotar turísticamente la Semana Santa tradicional, sino que además se ingenian nuevos actos culturales para dotarla de contenidos adicionales. Así, por ejemplo, hace apenas una quincena de años que se inició en Alcorisa una representación popular de El drama de la Cruz, que se ha ido repitiendo anualmente, y hoy esta representación de la Pasión constituye ya uno de los actos "tradicionales" de la Semana Santa de la ruta; en ella intervienen unos trescientos actores, todos ellos habitantes del pueblo. En la localidad de Berge, cerca de Molinos, también en el Bajo Aragón, el año 1992 se recuperó el Vía Crucis olvidado desde hacía más de un cuarto de siglo. Aquel año, en el deseo de enlazar con la tradición perdida, según nos relata la prensa local, se tuvo esmero en imitar en todo lo posible el último Vía Crucis realizado, de manera que se encomendó la tarea de llevar la cruz a cuestas a la misma persona que lo había realizado entonces:

Trajes antiguos que han permanecido más de 25 aǹos en las arcas, ataviarán nuevamente a los vecinos que participen en la procesión. [...] Domingo Orta, llevará a hombros, tal y como hiciera la última vez que se celebró este acto religioso, la pesada cruz de la Pasión a cuestas ${ }^{8}$.

Entre estos pueblos del Bajo Aragón, aquel que sin duda ha destacado más por la difusión de su Semana Santa ha sido Calanda. La fama de sus tamborileros, dados a conocer al mundo a través de la obra cinematográfica de Luis Buñuel, ha trascendido la comarca. Las diversas procesiones, como en tantas otras poblaciones españolas, forman parte importante de los actos de la Semana Santa calandeña. La primera se convoca el Jueves Santo y concluye con un Vía Crucis a largas horas de la noche. El viernes, a primera hora de la tarde, se realiza la Procesión de El Pregón, denominada así porque un pregonero va anunciando la próxima muerte de Jesucristo, y por la noche, se forma la Procesión de la Soledad, protagonizada por la cofradía de La Dolorosa, agrupación formada por jóvenes mujeres solteras que son las que se encargan de llevar a hombros una imagen de Nuestra Señora de los Dolores. El sábado, sale a la calle la última procesión, conocida por el nombre del Santo Entierro. En todas las procesiones se alinean centenares de calandeños haciendo percutir los bombos y tambores. Todos ellos van vestidos con túnicas moradas y se cubren la cabeza con un tercerol. La población de Calanda da una cierta importancia al color morado de las túnicas

B Heraldo de Aragón, 16-IV-92, p. 7 (especial Semana Santa). 
de su Semana Santa, dado que se trata de un rasgo distintivo que la diferencia de la mayoría de los pueblos de la comarca que las llevan de color negro? Actualmente, las túnicas moradas constituyen un elemento importante del tipismo de la Semana Santa, de manera que su uso en las procesiones es incluso obligatorio por normativa municipal.

Uno de los actos centrales de la Semana Santa de Calanda es la denominada Rompida. Buena parte de la población, vestida con sus túnicas moradas, se concentra el mediodía del viernes en la plaza mayor, y a las doce en punto, todo el mundo a la vez, empieza a tocar los tambores y bombos: se "rompe la hora. La masa de instrumentistas se distribuye en círculos irregulares, según cofradías o grupos de amigos que, de manera independiente, van batiendo la media docena larga de diferentes ritmos o "toques" que se usan en la población. Esta actividad es proseguida por aquellos que tienen más fortaleza y ánimos - hombres y mujeres- hasta las dos del mediodía del día siguiente, después de haberse pasado toda la noche rondando con los instrumentos de percusión.

La costumbre de hacer sonar de forma masiva el bombo y el tambor durante las fiestas de Semana Santa no es demasiado antigua, a pesar de que con mucha frecuencia, a los medios de comunicación les gusta hablar frívolamente de "sonidos ancestrales". Parece que la primera noticia que se tiene de la costumbre proviene del año $1856^{10}$, y se habla de Mosén Vicente Allanegui, rector de Calanda de principios de siglo, como un decisivo promotor de los tambores. En Calanda, hasta hace pocos años había predominado el bombo, actualmente, no obstante, los tambores son mucho más numerosos. Antes se usaban instrumentos caseros hechos de madera y cuerda, y no importaba demasiado el tipo de utensilio que se utilizara - una lata de sardinas por ejemplo-, cuando no se contaba con demasiados recursos económicos. Hoy, no obstante, los tambores "son más buenos porque hay más dinero", y la gran mayoría de ellos son de elaboración industrial.

Tocando los instrumentos, hay personas que sangran con una relativa facilidad, hecho que se espectaculariza notablemente por los medios de comunicación. Las heridas se producen con el roce $\mathrm{y}$, aunque sean de hecho minúsculas, poseen una cierta aparatosidad. Siempre hay malas lenguas que aseguran que la gente se produce las heridas expresamente. La realidad es que después de hacer sonar los instrumentos con insistencia durante horas y horas, no resulta difícil ni ilógico ver manos sumamente

9 Parece ser que la túnica morada se comenzó a utilizar en Calanda el año 1920. Anteriormente era de color azul o negro. Cfr. Manuel SANZ y MARTinez, Calanda. De la edad de piedra al siglo $\mathrm{xx}$ (Reus, 1970), p. 38.

10 Cfr. M. SANZ, op. cit., p. 37. 
hinchadas y cubiertas con emplastos. Son pocas las personas, y en este caso mayoritariamente mujeres, que tocan con guantes. Comentarios como se ponen locos tocando o sla gente arde cuando oye los tambores" son habituales entre la población cuando quieren explicar su fiesta a un forastero. Se dice de los diferentes toques que se llevan en la sangren, y a todo calandeño se le pone la piel de gallina con sólo oírlos. La gente comenta orgullosa los casos de muchas personas nacidas en Calanda que al encontrarse lejos del pueblo por Semana Santa, piden por conferencia telefónica que les hagan oír los bombos por unos breves momentos.

La Semana Santa de Calanda adquiere actualmente un cariz de verdadera fiesta mayor. Los balcones aparecen engalanados con banderas españolas, algunas aragonesas y trapos blancos. Los jóvenes hablan de slas fiestas", no de semana Santar. Los bares se llenan a rebosar, las discotecas funcionan hasta las últimas horas de la noche con permiso municipal, e incluso se monta, para los días de la Semana Santa, una feria con las estereotipadas atracciones de tíovivos, tiro al blanco y otros entretenimientos, así como los acostumbrados puestos de quincalla y golosinas regentados por vendedores ambulantes. Las churrerías hacen su agosto y los más pequeños se desviven por conseguir los globos multicolores de los vendedores. De hecho, la fiesta mayor del pueblo cae por el Pilar, pero hoy día, a diferencia de antes, se da mucha más importancia a la Semana Santa: "Ahora se vive más", hay más ambiente en Semana Santar. De acuerdo con la dinámica propia de las fiestas mayores rurales, la persona oriunda de Calanda, que por razones de trabajo o estudios reside fuera de la población, abandona por unos días su domicilio habitual de Zaragoza, Cataluña o Francia para vivir su Semana Santa en el pueblo.

Actualmente, son numerosos los turistas que visitan la Semana Santa de Calanda. Muchos de ellos se extrañan por la alegría y jolgorio - verdaderos aires de fiesta mayor- que acompanan la celebración. Por la calle, exceptuando las procesiones, hay realmente pocos signos externos de religiosidad, aunque los diversos actos que se celebran en la iglesia sean realmente multitudinarios. Es una fiesta muy vivida por la población. En ella participa de manera activa gente de todo estado, sexo y condición social. Desde el campesino octogenario hasta los chiquillos, desde la madre de familia hasta los jóvenes que cursan sus estudios en Zaragoza o Barcelona. Las mujeres de edad son las que menos se dejan ver con un bombo o tambor en las manos. De hecho, la integración de la mujer en las tamborradas constituye un hecho bastante reciente. Aún ahora hay quien no ve demasiado bien que las mujeres intervengan en estos actos.

La Semana Santa de Calanda es realmente una fiesta popular que articula hoy día el momento colectivo más importante de la población. Muchos tamborileros están organizados en cofradías que han visto crecer su número 
en los últimos años. Actualmente hay nueve, y alguna de ellas cuenta con más de trescientos miembros. La más antigua -lade El Santísimo- fue fundada en el siglo xvir y la más moderna, quedata de 1991, está constituida por un centenar de personas y formada básicamente por matrimonios jóvenes. Días antes de Semana Santa,las personas que pertenecen a las diferentes cofradías se reúnen para practicar los toques de bombo y tambor. Dado que existe una cierta rivalidad, es preciso no haber escatimado tiempo en los ensayos previos para poder realizar así un buen papel en los actos de la Semana. Las cofradías desfilan en las procesiones con la túnica morada de rigor; el único detalle que distingue los miembros de las cofradías del resto de la población es un pequeño escudo que los primeros llevan cosido en la túnica.

El carácter participativo que se quiere dar a la fiesta de Calanda se pone de manifiesto en un bombo de dimensiones gigantescas que el Ayuntamiento de la localidad instala en la plaza mayor desde el año 1973, para que lo pueda tocar quien lo desee. Y cualquier persona venida de fuera que, provista de bombo o tambor, se quiera añadir a la batahola calandeña es siempre bien aceptada. Esto no excluye, no obstante, que a los habitantes de Calanda les desagrade cualquier tipo de acto o comportamiento que no se adecúe a los patrones habituales de conducta de su Semana Santa. En el pueblo nadie baila cuando se hacen sonar los bombos y tambores, y más de un forastero ha sido increpado por hacerlo. De hecho, se exteriorizan a menudo quejas sobre la "actitud irreverente y desconsiderada de buena parte de esa gran multitud que todos los años acude a vernos" ${ }^{11}$.

A pesar del cariz participativo que ofrece la tamborrada, está claro que difícilmente puede ser asumida totalmente por quien no pertenece a la colectividad. A los calandeños les gusta remarcar que ael barullo sólo lo entiende la gente del pueblo" y, efectivamente, tienen razón. A la gran mayoría de turistas les cuesta creer que una persona pueda estar percutiendo estos instrumentos sin pausa durante veinticuatro horas y, además, pasárselo bien con ello. La fiesta no es concebida en primer lugar como espectáculo, pero esto no obsta para que los mismos autóctonos le otorguen un cierto valor estético y que, por tanto, pueda ser considerada -además de fiestaespectáculo. El Ayuntamiento se cuida de dar unas mínimas directrices para preservar este valor. En las procesiones puede participar cualquier persona, siempre, no obstante, que vaya vestida con la túnica morada y el atercerol, y al margen de la puntual intervención de la banda de música en alguna procesión, no se permiten otros instrumentos que los bombos y tambores.

Hoy, la Semana Santa de Calanda ha entrado ya de lleno en los canales comerciales folklorísticos. Los periódicos, tanto locales como estatales hacen

1 Emilio BROC, „¿Cultura o marketing...?, El Dia de Teruel, 16-IV-92, p. 25. 


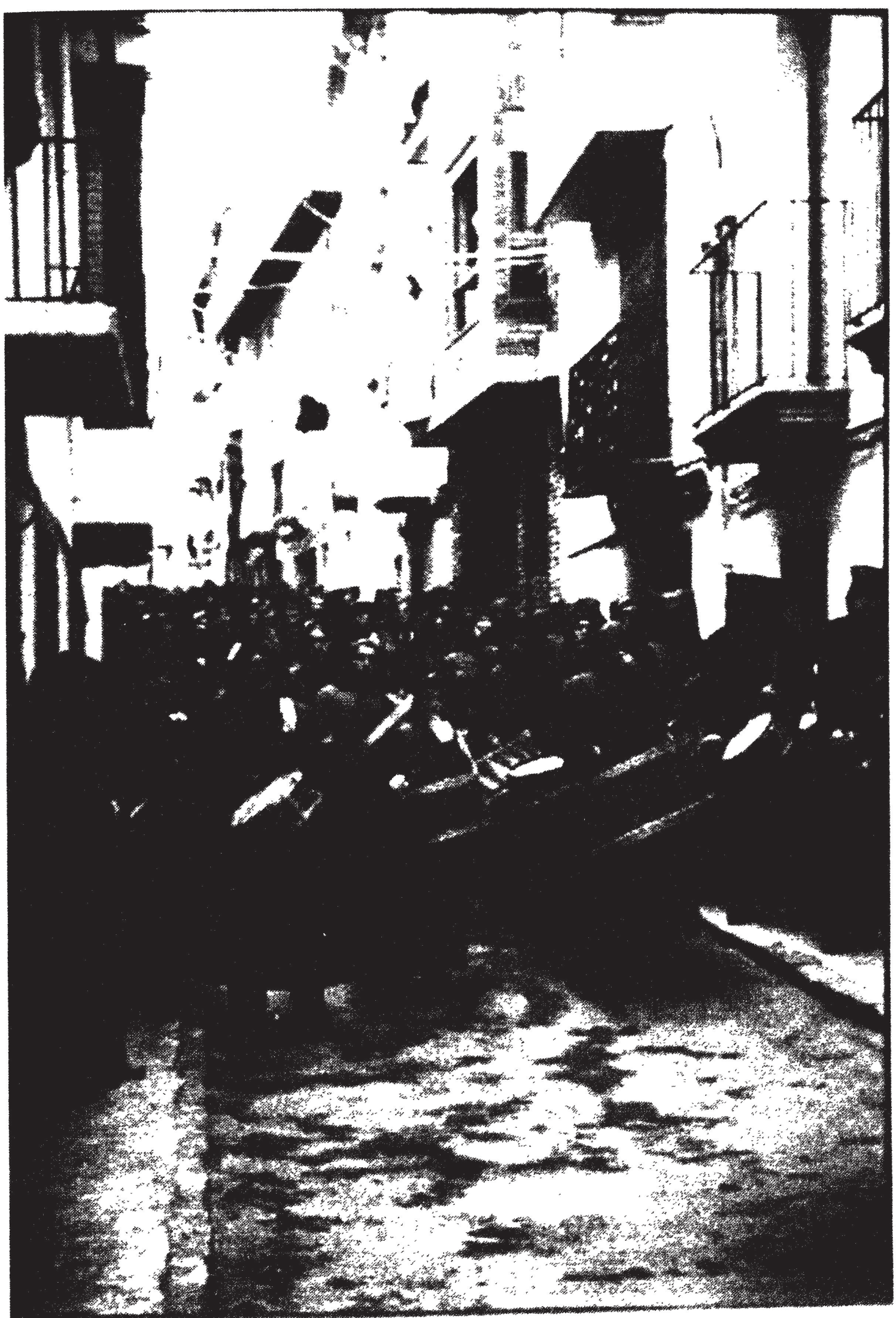

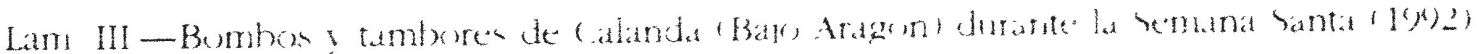


amplio eco, también las televisiones e incluso los medios de comunicación extranjeros ${ }^{12}$. Los resultados son en cifras comerciales francamente positivos. Las plazas hoteleras de aquella comarca bajo aragonesa resultan claramente insuficientes, y en los pocos restaurantes de la población guardar turno será el paso previo obligado antes de tomar cualquier refrigerio. La industria del "Souvenir" no se queda atrás. Se venden figuritas representando los tamborileros, tambores y bombos en miniatura, mazas de bombo genuinas y de imitación, llaveros, bolsas y camisetas con decoraciones alusivas a la Semana Santa local, grabaciones videográficas de los diversos actos y, en las tiendas de índole más diversa, se pueden adquirir diferentes tipos de tambores, todos ellos, no obstante, de fabricación industrial.

La Semana Santa de Calanda ha surgido en el mismo pueblo y es una fiesta para la población, pero desde que, al mismo tiempo, se vende como "folklore" pertenece también a los visitantes. A pesar de que, de vez en cuando, su masiva afluencia sea criticada por algún ilustrado local, el turista se ha convertido también en un punto de referencia que acabará incluso siendo indispensable para la propia dinámica de las fiestas. Ante esta folklorización, es de esperar, en un futuro cercano, una gradual transformación de los diversos actos para irse adaptando a las necesidades y gustos de los visitantes. Pensemos, por ejemplo, en las fiestas de localidades rurales que ya hace tiempo han sido "descubiertas" por la ciudad. A finales de siglo pasado, ya se entendía la fiesta de la Patum de Berga, una de las más populares celebraciones del Corpus de Cataluña, como un posible reclamo turístico para la población ${ }^{13}$, y la idea de que podía haber público venido de fuera ya incidía de manera directa en la concepción de la fiesta. En un artículo publicado en la Crònica de Berga el 24 de mayo de 1884, el autor se quejaba de la poca presentabilidad de los personajes de la Patum y se hablaba del mal efecto que esto podía causar en los visitantes:

[...] Por lo cual, entendemos que debe pensarse en una reforma radical de vestidos y equipos, para las Patums de los años venideros, si no se quiere impresionar mal a los forasteros que en estos días nos honran con su presencia ${ }^{14}$.

En Berga, ya se adaptó el programa de la Patum de 1895 a los horarios y a las conveniencias de los esperados visitantes ${ }^{15}$.

12 Véase por ejemplo el extenso artículo de propaganda turística de Johannes WINTER, "Die Trommeln von Aragón*, publicado en el semanario alemán Die Zeit, núm. 16, 10-IV-92, p. 82. p. 48.

13 Cfr. Josep Noguera I CANAL, Visió bistòrica de la Patum de Benga (Barcelona, 1992),

${ }^{14}$ Citado por J. Noguera, op. cit., p. 48.

15 Cfr. J. NOGUERA, op. cit., p. 57. 
El renombre que los tamborileros de Calanda han conseguido a través de sus actuaciones en la Semana Santa hace que, de acuerdo con la dinámica del actual folklorismo, de vez en cuando, sean solicitados para tocar fuera de la población, ya sea en otras localidades de las comarcas vecinas, en Cataluña ${ }^{10}$ o incluso en el extranjero, "ultrapasando" de esta manera, tal como es propio en el folklorismo, los marcos espaciales y temporales tradicionales de su actividad ${ }^{17}$. Actualmente, los tamborileros han pasado a ser un verdadero elemento simbólico de la localidad, y cumplen con ello para Calanda la misma función representativa que la imagen del templo de la Sagrada Familia, la Tour Eiffel o una vista del barrio de Manhattan para Barcelona, París o Nueva York respectivamente. Gracias a esta nueva carga semántica de representación colectiva, los bombos y tambores de la Semana Santa de Calanda hicieron acto de aparición en la masiva manifestación autonomista reivindicativa del 23 de abril de 1992 en Zaragoza, que congregó a miles de personas. Y también, a causa del valor simbólico y folklorístico adquirido en las últimas décadas por los bombos y tambores del Bajo Aragón, ya ha habido más de una rencilla entre la poblaciones de la comarca por cuestiones de "denominación de origen. En un artículo del diario El Día de Teruel, aparecido el mes de abril de 1992, podemos leer lo siguiente: "[Los tamborileros tienen] una gran responsabilidad en el futuro de nuestra tradición, tan en peligro de sernos hurtada y que están reclamando ya como propia desde otros lugares" ${ }^{18}$.

En este caso se hacía referencia a la localidad de Alcañiz. No es preciso decir que cuando se habla de Alcañiz como la cuna de estas tradiciones no se hacen esperar las protestas de las otras comunidades vecinas ${ }^{19}$. Hoy día.

16 Los tamborileros de Calanda, en los últimos aǹos, han actuado en diversas ocasiones en Cataluña, incluso en los actos oficiales de la ceremonia inaugural de los Juegos Olímipicos de Barcelona. En este pueblo del Bajo Aragón, se cuenta como anécdota la visita que efectuó en una ocasión el alcalde de Barcelona a la localidad. Después de presenciar una tamborrada, Pasqual Maragall, profundamente impresionado por el espectáculo, se interesó por la cantidad de dinero que había costado la organización del acto. Su sorpresa no fue pequeña cuando se le dijo que se trataba de una manifestación popular que no costaba ni un duro al tesorero del Ayuntamiento. Quién sabe si esta anécdota tiene algo a ver con el hecho de que los tamborileros de Calanda participasen en un puesto tan honorífico en los espectáculos inaugurales de los Juegos Olímpicos.

17 En 1970 se escribió sobre los tambores de Calanda lo siguiente: "En el año 1860, salieron los tambores para celebrar y festejar la entrada del Ejército Español en Tetuán. Es la primera y única vez en su historia, que los tambores de Calanda han salido a la calle en días distintos de los de Semana Santa. (M. Sanz, op. cit., p. 37). Hoy día, pues, las cosas son ya muy diferentes.

18 El Día de Teruel, 16-IV-92, p. 22.

19 Véase, por ejemplo, El Día de Teruel, 16-IV-92, p. 25. 
los tamborileros del Bajo Aragón han devenido «patrimonio", y cualquier tipo de patrimonio resulta siempre incómodo de compartir.

Los ejemplos de manifestaciones festivas procedentes de Verges, l'Alguer y Bajo Aragón que, a lo largo de estas páginas, hemos mencionado, se hallan sólidamente enmarcados en los actos de Semana Santa, y, por esta razón, a pesar del uso folklorístico que de ellos se hace, el contexto formal de índole religiosa está bien presente. En todos estos casos, nos encontramos con el aprovechamiento por parte del folklorismo de unas tradiciones que no han perdido el hilo de la historia. El folklorismo, no obstante, no es tan solo capaz de recuperar lo que parecía que se iba a perder irreversiblemente, dotándolo de un nuevo significado, sino que también es capaz de inventar.

Hoy día se celebra en la localidad de Porreres —una población de unos cinco mil habitantes, situada en el sudeste de Mallorca - la fiesta anual de Santa Catalina. Se trata de una celebración de carácter exclusivamente lúdico en la que se combina la realización de varias hogueras - elemento hondamente enraizado en el folklore mallorquín-la música y el baile (tanto de corte tradicional como moderno) y la consumición en colectividad de diversos productos culinarios que se consideran típicos para la ocasión. La fiesta tiene un indudable espíritu atradicionaln, y cualquier visitante foráneo a la población que casualmente se encontrase en ella no dudaría en adscribirla ipso facto al acervo del folklore local. Su examen detenido, no obstante, da como resultado que el epíteto de tradicional que se atribuye a la fiesta no es exactamente el más adecuado - al menos en su sentido más estricto- sino que más bien debe ser considerada como producto directo del actual interéspor la recuperación de un pasado étnicamente diferenciado. Se manifiestan aquí de manera plena algunas de las características fundamentalesdel folklorismo. Las connotaciones religiosas de esta fiesta se han reducido a la mínima expresión posible ya que, más allá de su denominación,no conserva en la actualidad ningún rasgo propio de la religiosidad tradicional.

Lo primero que sale a relucir conversando con los organizadores de la fiesta de Santa Catalina de Porreres es la antigüedad de la celebración. Pero para ello no se remiten a su propia experiencia o a lo que se haya podido oír decir a las viejas generaciones, sino a unas vagas referencias contenidas en el libro Noticias históricas sobre el santuario de Montesión de Porreras de Joan Feliu, editado el año 1804, donde se nos dice que en este santuario cercano a la ciudad, los estudiantes de gramática que allí residian tenían por costumbre hacer una gran hoguera en la noche anterior a la festividad de Santa Catalina ${ }^{20}$. En la misma publicación se indica, además, que en la

20 Cfr. Joan FeLuU, Noticias bistóricas sobre el santuario de Montesión de Porreras (Palma de Mallorca, 1804), p. 69. 
población de Porreres también había existido esta tradición aunque ya entonces se encontraba extinguida: "Hasta no muy lejanos tiempos ha existido en esta villa la costumbre de hacer muchas hogueras («binerbos") la víspera de Santa Catalina. ${ }^{21}$.

Privada, pues, de continuidad histórica, la actual fiesta de Santa Catalina de Porreres es una de tantas fiestas recuperadas, y hasta un cierto punto incluso podríamos decir inventadas", tal como tendremos la ocasión de ir viendo a lo largo de la presente exposición.

En el año 1975, un grupo de entusiastas vecinos de Porreres tuvo la idea de resucitar la fiesta. Hacía ya más de dos siglos que había desaparecido la conmemoración y ya nadie sabía exactamente cómo había podido ser la antigua, aunque por los comentarios de Joan Feliu resultaba claro que el fuego tenía que constituir su epicentro y el elemento articulador. Tenemos que decir también que, en Porreres, lo que todavía se encuentra bastante fresco en la memoria de sus habitantes son las tradicionales fiestas de ases matances" (matanza del cerdo) que empezaban a hacerse precisamente por la época de la festividad de Santa Catalina, en noviembre, y en las que en principio, tal como es habitual en muchas localidades mallorquinas, se cantaba, se bailaba y se consumían en la colectividad y al aire libre productos derivados del cerdo que eran asados en hogueras.

Para dar forma, pues, a la fiesta de Santa Catalina que se pretendía recuperar, se recurrió a todos aquellos elementos estructurales propios de ases matances", fiestas sin fecha fija que en la actualidad ya no se celebran, a los que se añadió la idea de "tradicionalidad. y de ccontinuidad" mediante su inclusión bajo la advocación de Santa Catalina. De esta manera, surgió de las viejas cenizas una fiesta nueva, o mejor dicho, se inventón una fiesta antigua.

Recuperada, pues, la fiesta en 1975 , se celebra durante la noche del sábado más cercano al día de Santa Catalina ( 25 de noviembre). Desde su recuperación, se ha ido afianzando y modificando ligeramente con el paso de los años. Según podemos deducir de la breve alusión de Joan Feliu al recuerdo que quedaba en 1804, antiguamente se hacían muchas hogueras preparadas por diferentes grupos de vecinos delante de sus casas. En la moderna fiesta de Porreres esto ya no era posible. Las hogueras representan un problema para la conservación del moderno asfaltado de las calles, y tampoco se podía esperar una participación masiva y espontánea de la población cuando la fiesta, de hecho, ya había perdido el hilo de la historia. Así, pues, se escogió como marco festivo la pequeña plaza de toros de la población. Si en un principio se levantó una sencilla hoguera, en el año 1988, el núcleo infraestructural de la fiesta ya había aumentado algo su complejidad.

${ }^{21}$ Ibidem. 
En el centro de la plaza se levantó un monumental abinerbon ${ }^{22}$, es decir, una hoguera constituida por ramaje fino -zarzas principalmente- dispuesto de manera muy apretada. Equidistantes y colocadas en los extremos de la plaza había tres hogueras, también de considerables dimensiones, hechas a base de troncos y tocones. No demasiado alejada del abinerbon, se emplazó aún otra hoguera de ramas finas apiladas y coronadas por un motivo temático que representaba una escena campesina de la matanza del cerdo. Esta "falla" nos servimos de la terminología valenciana ${ }^{23}$ - estaba constituida por varias figuras artísticamente elaboradas que hacían alusión al momento del sacrificio del animal: Un cerdo construido con un armazón de alambre y revestido de algodón que se hallaba rodeado por tres payeses con cabeza de pasta de papel, tocados con gorra campesina y vestidos con ropa vieja.

De hecho, 1988 - año en el que se basa esta descripción- fue la primera ocasión en la que, entre las hogueras más tradicionales de la fiesta, se incluía una "falla", innovación muy bien recibida por los asistentes. Antes de que el público empezase a fluir masivamente, se encendieron sin ningún tipo de solemnidad especial las tres hogueras formadas por gruesos troncos y que estaban situadas en los extremos de la plaza. La gente, buscando el calor, iba tomando asiento a su alrededor y se empezaron también a preparar los asados a base de "llonganissa" (sobrasada) y "botifarrons" (morcillas). Esta comida se expendía en un tenderete dispuesto en un ángulo de la plaza, aunque también había vecinos que se la traían de casa. Además de lo que se asaba en las hogueras, se podían adquirir también las típicas cocas mallorquinas, rellenas de verduras, así como algunas bebidas alcohólicas entre las que no podían faltar los populares alicors d'herbes".

Cualquier fiesta resultaría incomprensible sin su música, y este importante elemento tampoco podía faltar, pues, en la de Santa Catalina de Porreres. El análisis del repertorio musical nos da una buena idea de la naturaleza de la fiesta. Encima de una tarima preparada para la ocasión, un grupo de intérpretes tocaba música arock". La fiesta de Santa Catalina tenía que estar puesta al día y los organizadores, con buen conocimiento de causa, sabían que para garantizar el éxito tenían que conquistar a la juventud. Se reservó, no obstante, un buen espacio a los aires tradicionales. El grupo musical, sin embargo, no estaba constituido por un grupo de aficionados de la localidad, sino por un conjunto de elementos jóvenes, musicalmente bien preparados y conocedores del "folk" isleño. Su música, constituida básicamente por copeos, fandangos, jotas y "mateixes" también fue bailada. Evidentemente, este ele-

22 La palabra abinerbo", de etimología no todavía del todo esclarecida, se utiliza tan sólo en las localidades mallorquinas de Porreres y Montuïri.

23 En Porreres se la denomina sencillamente afogueró (.hoguera-). 
mento formal resultaba imprescindible en una fiesta que clama por su .tradicionalidad. Entre las actuaciones musicales, se leyó, además, un "testament des porc" (testamento del cerdo"), al estilo de los testamentos carnavalescos, elaborado expresamente para la ocasión.

Poco antes de medianoche fue encendida la falla que ardió rápidamente ante las miradas de un público embelesado. Poco rato después se encendió la "vedette" de la fiesta: el abinerbo". Para ello se solicitaron los servicios del "dimoni gros" un personaje típicamente mallorquín que habitualmente hace aparición en las fiestas de San Antonio de enero ${ }^{24}$. El "dimoni gros" encendió ceremoniosamente el "binerbo" cuyas activas y altas llamas iluminaron por unos momentos todo el espacio de la plaza. Con esto se dio la fiesta prácticamente por concluida.

Vista esta descripción somera de la fiesta de Santa Catalina, pasemos a analizar aquellos aspectos que nos permiten calificarla de fenómeno folklorístico. Para ello tendremos que centrar nuestra atención principalmente en el ámbito morfológico, ideacional y funcional.

Sabida es la importancia que actualmente da nuestra sociedad a su pasado étnicamente diferenciado, hecho que es al fin y al cabo uno de los principales focos generadores de folklorismo. No obstante, para que podamos hablar de folklorismo con pleno derecho en un caso concreto, es imprescindible la presencia de una consciencia de tradición, la cual habrá que mantener, revitalizar o recuperar. Este es el caso por lo que respecta a nuestra fiesta de Porreres. Hoy día, todo habitante de esta localidad mallorquina conoce la antigua existencia de la fiesta, aunque tal como ya he explicitado anteriormente, esto es así no por continuidad de la memoria histórica colectiva, sino por referencias conseguidas hurgando en el pasado a través de las fuentes documentales escritas. A esta actitud positiva hacia el pasado local se añade siempre un cierto activismo, reflejado a la perfección en frases al estilo de "Hem de procurar guardar tot lo nostro amb gelosia" ${ }^{25}$ que se oían constantemente en boca de los organizadores.

De hecho, el pasado histórico de cualquier población ofrece numerosos puntos susceptibles de querer ser reivindicados como atradición" por nuestra sociedad actual. El hecho de que una colectividad dada se decida por uno $\mathrm{u}$ otro de estos momentos históricos depende de diversas razones. Dos de ellas son, a mi juicio, importantes: el pragmatismo funcional y el mimetismo culturo-ambiental. Es decir, el hecho de que esta recuperación -al margen

24 El dimoni gros* es el cabecilla de los diablos mallorquines, que disfrutan todavía de una gran vitalidad en la isla. Salen a la calle principalmente con motivo de las escenas hagiográficas que se representan durante el día de San Antonio. En Porreres la presencia de los diablos en las fiestas de Sant Antoni actuales es bastante reciente (1987).

25 .Tenemos que procurar preservar todo lo nuestro con celo. 


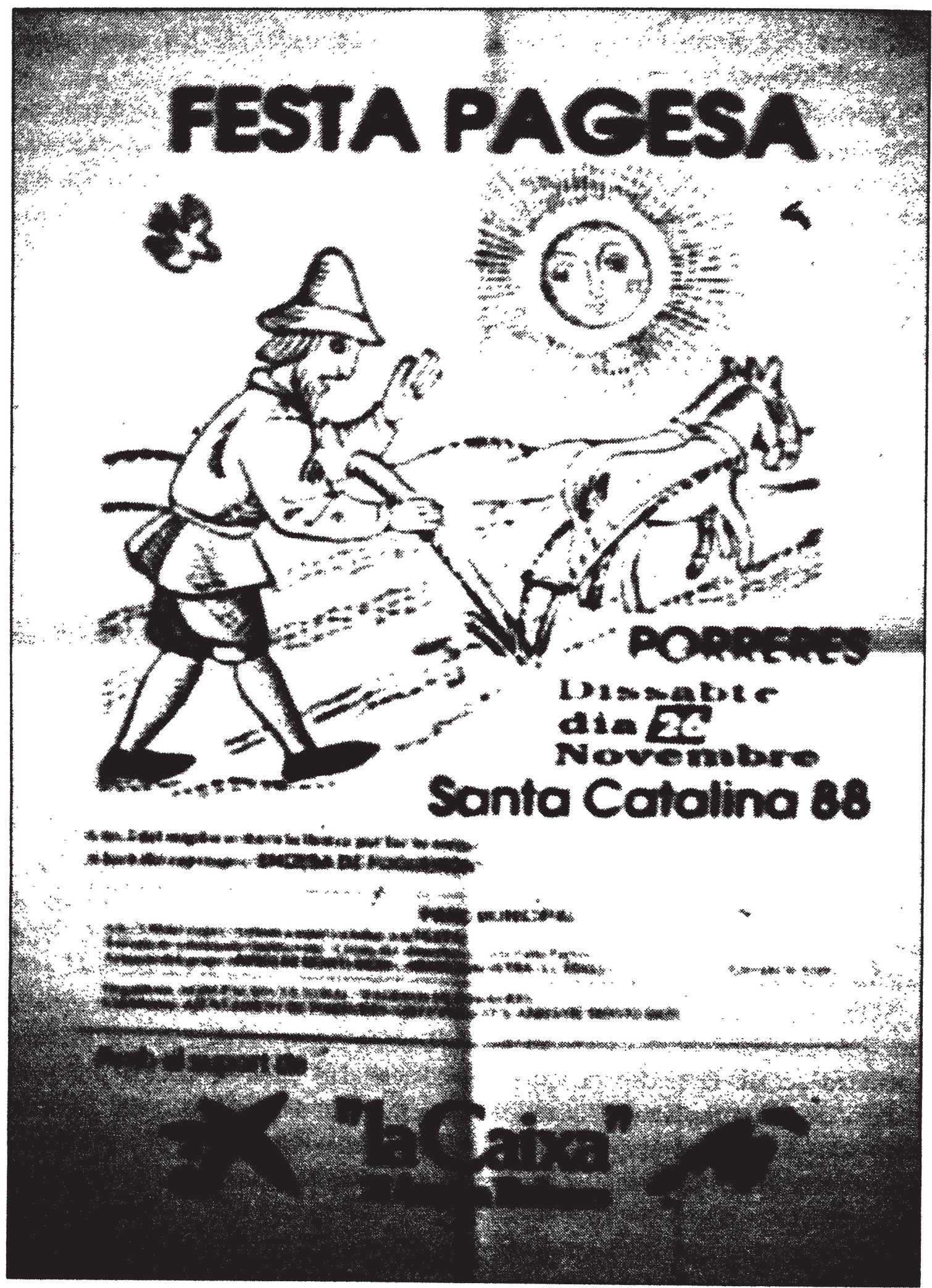

Lám. IV.-Cartel anunciador de la fiesta de Santa Catalina de Porreres (Mallorca) 
de su interés etnohistórico- pueda satisfacer determinadas necesidades sociales, y el hecho de que se encuentre todavía vigente en otros puntos del sistema étnico al cual la colectividad misma se adscribe. Estas dos razones resultan evidentes en el caso de la fiesta de Santa Catalina de Porreres, como también en los ejemplos anteriores que hemos podido ver a lo largo de estas páginas. El estado actual de nuestra sociedad posibilita y, a la vez, fomenta la creación de nuevos contenidos lúdicos y la recuperación de la antigua celebración de Santa Catalina, por lo que a Porreres se refiere, permite dotar de un nuevo espacio lúdico a su calendario local. Por otra parte, la recuperación de la fiesta es fuertemente estimulada por el hecho de que el mismo patrón formal de la celebración -un conjunto de actos festivos articulados alrededor de las hogueras tradicionales - se encuentra muy extendido en Mallorca, ya sea centrado en la misma fecha de Santa Catalina (Campos, Llombards, Setsalines), o bien en otras, entre las que descuella claramente la fiesta de San Antonio Abad ${ }^{26}$.

El concepto de "tradición" implica las ideas de antigüedad y genuinidad, y éstos son algunos de los requisitos que debe intentar satisfacer toda manifestación folklorística. Esta genuinidad habrá que preservarla, aunque en el mundo del folklorismo evidentemente no se la entienda según el rigor histórico positivista, ya que lo más habitual es que sea aplicada únicamente en el ámbito formal y, aún así, a menudo no sobrepasa el nivel de lo anecdótico. Por lo que a nuestra fiesta en concreto se refiere, la nota genuina la daban todos aquellos elementos tradicionales que la configuraban, y se advertía por parte de los organizadores un constante deseo de cuidar este aspecto. Recuerdo, por ejemplo, mis conversaciones con uno de los organizadores más activos y entusiastas, un campesino que había dejado las labores agrícolas para pasar a ser funcionario del Ayuntamiento, que se me quejaba de la importancia, siempre mayor, que en la fiesta iba tomando el cava, desplazando al buen vino de la tierra. El cava - según sus palabrasnada tenía que ver con la producción vitícola isleña $\mathrm{y}$, por tanto, era partidario de suprimirlo en la fiesta del próximo año, para así mantenerse aún más fieles a la tradición.

Otro de los aspectos que más se recalcaban de la fiesta de Santa Catalina era su carácter de .festa pagesan, es decir, «fiesta campesina. a pesar de que Porreres - con sus cinco mil habitantes- ya no es el prototipo ideal de una ciutat pagesa. El programa anunciador de 1988, por ejemplo, aludía a esta idea de manera clara y contundente. El epígrafe festa pagesa* encabezaba

26 Cfr. Josep MARTf I PÉREZ, "El fuego en el mundo tradicional de las islas Baleares", J. M.' FericGla (ed.), El fuego y sus ritos en los países de la Corona de Aragón (Barcelona, 1990), pp. 113-115. 
con grandes carácteres tipográficos el programa que, además, estaba ilustrado con un grabado representando una escena rural. En la idea que tenemos de "folklore" no hay duda de que la ruralidad representa uno de los mejores conceptos para garantizar la autenticidad y genuinidad de una celebración. Ya desde los inicios del folklore como ámbito de estudio, se ha identificado no pocas veces de manera explícita o implícita la cultura popular con el ámbito rural. Esta tendencia hacia la fidelidad se verá, no obstante, continuamente confrontada con los requisitos de modernidad que, asimismo, deben acompañar a la fiesta, sin los que estaría, como tal, condenada al fracaso. Este intento de querer reconciliar o aunar las dos realidades diferentes se manifiesta de manera plena en el plano morfológico de la celebración.

Desde el punto de vista morfológico, el análisis de la fiesta nos da la impresión de encontrarnos ante una especie de "collage. La fiesta de Santa Catalina se compone de un conglomerado de elementos formales de diferente origen, dispuestos juntos no de manera aleatoria, sino siguiendo siempre los patrones ideacionales folklorísticos. Por una parte, podemos establecer una clara distinción entre elementos tradicionales, como los diferentes tipos de hogueras, el dimoni gros", el folklore musical, la comida y el "testamento del cerdo; por la otra, los elementos de claro corte moderno, entre los que destacan la música y el baile de moda que también estuvieron presentes, similares estilisticamente a los que podemos encontrar en cualquier discoteca del país.

El producto folklorístico no tiene que ser, por lo que a los aspectos formales se refiere, un producto museístico. Precisamente éste es uno de los rasgos principales del folklorismo, debido a su adscripción a una doble realidad: aquella que pretende evocar y la propia del contexto donde, de hecho, se produce. El folklorismo contiene elementos tanto de corte tradicional como actuales. Pero no es la presencia en la fiesta de la música y el baile modemos lo que fundamentalmente nos remite a la idea de folklorismo, ya que en principio se podrían ver sencillamente como elementos innovadores, algo perfectamente lógico cuando el folklore, en este caso una fiesta, se mantiene vivo. Dentro del espíritu folklorístico no hay duda de que la música de corte anglosajón-que nada tiene de tradicional para los mallorquines - puede recibir desde el punto de vista ideacional un valor negativo, pero, de hecho, se trata de la música actual con la misma relevancia social, por tanto, de la que se utilizaría en la hipotética antigua fiesta de Santa Catalina y que hoy denominamos stradicional.

Lo realmente indicativo y que nos permite detectar el fenómeno folklorístico en la fiesta es el tipo y el conglomerado de los elementos tradicionales que en ella se presentan. Es ahí, sobre todo, donde vemos -manipulación. de la tradición y, por tanto, folklorismo. Dentro de estos elementos tradicionales podemos hacer las siguientes distinciones: 
a) Elementos propios: se trata de los que ya encontramos en la vieja celebración original. En este caso sólo podemos contar a ciencia cierta con el ‘binerbo", aunque parece lógico pensar que también en las fiestas de Santa Catalina de antaño se cantara y bailara.

b) Elementos locales procedentes de otro tipo de celebración: la corta aparición del edimoni gros" y la lectura del "testamento del cerdo".

c) Elementos tomados de otra localidad: algunos tipos de "coques" y la sallar.

Ya que el "binerbo", constituye el único elemento tradicional que a ciencia cierta une la antigua celebración con la nueva, se le da en la fiesta actual una importancia estructural grande. El abinerbo" se erige en el centro de la plaza, recibiendo, pues, el sitio preferencial. Dado que quema con una relativa rapidez, debido al tipo de leña que lo compone, se enciende al final de la fiesta como colofón. Además, y a diferencia de las otras hogueras que adoman la velada, el abinerbo" se enciende ceremonialmente. El momento se ritualiza mediante el concurso del "dimoni gros" que es quien se encarga de aplicar la llama a la leña apilada.

Dentro de la fenomenología del folklore, encontramos ciertos elementos que son distintivos para una fiesta determinada, esto es, su presencia nos remite directa e indefectiblemente a la fiesta a la cual pertenecen. Pensemos, por ejemplo, en el pesebre navideño, las hogueras de San Juan o en los tradicionales "panellets" que se consumen durante el Día de Todos los Santos en Cataluña. Estos elementos tienen el rango de verdaderos signos indexicales ya que su presencia nos remite automáticamente a la fiesta de la cual forman parte. En un cartel anunciador, por ejemplo, basta ver uno de estos elementos formales para que sepamos inmediatamente a qué fiesta hacen referencia. Otros elementos, en cambio, tienen el estatus de comodín ya que pueden pertenecer a diferentes celebraciones. Por ejemplo, el baile de copeo y jotas en Mallorca no es un rasgo distintivo - aunque típico- para las fiestas de San Antonio, ya que también forman parte del ambiente festivo de otras muchas celebraciones, como la de Santa Catalina de Porreres, descrita líneas más arriba. Los elementos distintivos son de gran importancia a la hora de querer recuperar una fiesta; son los que le dan personalidad y justifican formalmente su existencia.

En la fiesta de Santa Catalina de Porreres, se asigna al tbinerbor cada vez más la función de elemento distintivo porque al haber desaparecido en las últimas décadas la costumbre de celebrar las fiestas de ases matances" en las que también se erigían monumentales sbinerbos", actualmente este particular tipo de hoguera sólo se hace por Santa Catalina. De esta manera no debe extrañarnos en absoluto la importancia que se le otorga, y que, tal como ya hemos indicado, se manifiesta a través del orden espacial (ocupa el centro 
de la plaza), temporal (se le prende fuego al final de la fiesta) y también mediante el rito (es encendido por el adimoni grosn). Se trata de la misma función, al fin y al cabo, que también se otorga a la danza de la muerte en la población ampurdanesa de Verges, o los tamborileros vestidos con sus túnicas moradas en Calanda.

La presencia en la fiesta de Santa Catalina de Porreres de elementos tradicionales locales pero procedentes de otros tipos de celebraciones se explica por la ley de asociación. La lectura del stestamento del cerdo" constituye un acto claramente inspirado en los testamentos de Carnaval. En la fiesta de Santa Catalina se justifica su realización por el hecho de que, de alguna manera, la celebración ha heredado el espíritu de las fiestas de sses matances", en la que el cerdo era principal protagonista. También la efímera presencia del "dimoni gros" se explica por el principio asociativo. Los .dimonis", son, como ya he mencionado, un elemento propio de las fiestas de Sant Antonio, íntimamente asociadas en Mallorca a la quema de vistosas hogueras. Pero el hecho de que también sean típicas las hogueras en la fiesta de Santa Catalina permite la inclusión de estos personajes de la tradición aunque sólo sea a través de la presencia del principal de ellos: el «dimoni gros.

Pero en el folklorismo, además de los elementos tradicionales propios, también se recurre con frecuencia a otros ajenos. Dentro del ámbito culinario, es el caso de algunos tipos de "coques" mallorquinas, originariamente tradicionales en una población determinada y tomadas por otras, que, hasta el momento, no las tenían como propias, con la finalidad de dar una connotación de tradicionalidad adicional a la fiesta que se pretende recuperar o revitalizar. La hoguera con un motivo temático, generalmente de tipo satírico y que se ha popularizado con el nombre de "falla* constituye un elemento relativamente moderno en las Islas Baleares. En Porreres, tal como ya hemos visto, la primera sfallaw en la fiesta de Santa Catalina apareció en 1988, y la idea fue tomada de poblaciones vecinas que las erigen para las fiestas de San Antonio. Por el hecho de representar una innovación en Mallorca, no podemos esperar encontrar en la efalla" de la fiesta de Porreres un valor de tradicionalidad. Pero el valor estructural que aportaba en el conjunto de actos desarrollados en 1988 no era el mero ornamental, puesto que constituía un acertado recurso de ambientación. La falla representaba una escena pagesa" -concretamente la matanza del cerdo- y por tanto estaba plenamente acorde con el espíritu de la fiesta, en cuanto que hacía alusión al valor del ruralismo que, como ya he indicado, constituye una pieza fundamental en los aspectos ideacionales de la manifestación folklorística. Los recursos de ambientación son habituales en este tipo de manifestaciones culturales. Así, por ejemplo, en la Feria de Abril que los andaluces celebran en Cataluña, 
tal como sucede en Sevilla, no escasean los participantes vestidos con atuendos de Andalucía, y en los restaurantes donde se sirven comídas típicas. -en este caso se trataría de folklorismo culinario- se adornan muy a menudo las paredes con aperos agrícolas, hoy día ya desfasados.

El análisis de cada uno de los diferentes elementos que componen la fiesta de Santa Catalina nos descubre este carácter de "collage», esta variopinta mezcla de elementos tradicionales - locales o extralocales-y modernos. Pero no cabe ninguna duda de que, desde el punto de vista ideacional y funcional, se consigue un todo coherente, articulado mediante la idea de tradicionalidad, que es lo que al fin y al cabo permite la formación de un "producto folklórico" de nuevo cuño.

Para comprender bien la fenomenología folklorística debemos tener muy en cuenta la doble fuente de donde proceden los elementos tradicionales: a) el propio folklore local, con o sin respeto del contenido, función y parámetros espacio-temporales; y b) el corpus del folklore regional que se ha ido configurando a través del estudio y divulgación de mano de los folkloristas.

Este último punto me parece relevante porque es ahí, especialmente, donde se pone de manifiesto la artificialidad - no se entienda esta palabra en sentido peyorativo- del uso de determinados elementos tradicionales en el folklorismo. El corpus de folklore perteneciente a cualquier colectividad se va configurando de la mano de especialistas y estudiosos de manera paratáctica. Es decir, todos aquellos elementos que se consideran "folklore se van etiquetando, pongamos el caso, de "catalanes" por el mero hecho de cumplir el requisito de "tradicionalidad" y de haber sido hallados en una localidad perteneciente al ámbito geográfico que conocemos por "Cataluña. La ideología basada en parámetros de tipo étnico no nos presenta, sin embargo, este conjunto de fenómenos como el resultado de una aglutinación inorgánica, dictada por criterios espacio-temporales (ámbito geográfico y tradición), sino que los articula mediante la idea de un etéreo espíritu colectivo de tipo nacional, regional, municipal, etc. y los presenta como un todo homogéneo en el que el epíteto «catalán" (o también *ampurdanés", "barcelonés", etc.) significa algo más que una fría identificación con meros accidentes geográficos. Una determinada población catalana, por ejemplo, asumirá como suyo el Costumari de Joan Amades por el único hecho de ser una recopilación de usos y costumbres relativa a Cataluña, a pesar de que en él se hallen prácticas tan extrañas para la población en cuestión como le resultarian las pertenecientes al folklore vasco o gallego.

De esta manera se constituye una especie de abote de manifestaciones folklóricas catalanas, un corpus de tradiciones, cuyo contenido, en virtud de la mecánica folklorista, puede ser reivindicado por cualquier subsistema (una 
comarca, un municipio, etc.) que se considere formando parte del sistema general, es decir, de Cataluña, aunque en realidad no haya pertenecido nunca a su propia tradición local. Gracias a esta identificación con el corpus general de folklore establecido -en cuya formación también se ha participado-, se justifica una coyuntural y selectiva redistribución del "bote" acumulado (de elementos tradicionales) cuando ello se crea de interés. Evidentemente, esto no sucede con cualquier tipo de elemento folklórico. Cuando su localización es demasiado estricta, difícilmente se podrá hacer uso de él, pero sí, en cambio, resulta más fácil hacer este transvase cuando se trata de un fenómeno cultural de mayor difusión. Es el caso, por ejemplo, de los «diables" en Cataluña, manifestación de la cultura popular que está experimentando una gran proliferación. Hoy día, son muchas las poblaciones que recurren a ellos, constituyendo incluso grupos propios estables, a pesar de no haber pertenecido nunca a la propia tradición del lugar. En una fiesta de tipo atradicional", la aparición de estos diablos no desentonará en absoluto, porque se les considera parte del corpus del folklore catalán, pero difícilmente se intentaría la incorporación de elementos procedentes de la tradición castellana, gallega o portuguesa.

La consciencia de tradición y el deseo de recuperar lo perdido implica lógicamente la voluntad de mantenerse, hasta un cierto punto, fiel al pasado -o a la idea que de él se tiene-. Esta fidelidad se pondrá de manifiesto principalmente en los aspectos formales, ya que éstos, frente a los de contenido o funcionales, son mucho más tangibles y, por tanto, más fáciles de manipular; además, no debemos olvidar que la pertenencia del folklorismo a dos realidades diferentes - su compromiso con una sociedad pasada y la actual - tiene que reflejarse por fuerza en una cierta mutación en los aspectos semánticos y funcionales.

En páginas anteriores ya he hecho alusión a la pérdida de contenido estrictamente religioso de la Semana Santa de l'Alguer, de Verges o del Bajo Aragón a pesar de la firme voluntad de sus poblaciones por impedir su desaparición, preservando y potenciando los aspectos formales. En estas celebraciones se incluyen en la actualidad elementos lúdico-festivos que se hallan en contradicción con el espíritu de luto que tradicionalmente era inherente a la Semana Santa y que, aunque hoy ya estén perfectamente integrados, no dejan de repeler a la población de más edad de estas localidades. El caso es mucho más acusado en la fiesta de Santa Catalina de Porreres. A pesar de tratarse de una fiesta sujeta nominalmente a la advocación de una de las santas más populares en Europa durante la Edad Media y muy venerada por los mallorquines, en la actualidad no encontramos ninguna connotación religiosa. Tampoco podemos encontrar ningún vestigio de rituales o creencias de tipo mágico, lo que no es raro hallar en las manifestaciones ígnicas tradicionales. Ni se da una significación especial a la 
altura que consiguen las llamas del "binerbo" ${ }^{27}$, ni se salta el fuego para favorecer la fecundidad de las parejas, ni tampoco se recogen las cenizas con fines apotropáicos. La celebración se asocia a la festividad de Santa Catalina, pero no por motivos religiosos, sino por el valor de tradición y continuidad que ello implica. Todos estos aspectos funcionales de tipo credencial, ya sean mágicos o religiosos, han perdido en buena parte relevancia social y, por tanto, aunque ello fuese posible, nadie piensa en su recuperación. A los habitantes de Porreres, sólo les interesó rescatar del pasado aquellos aspectos formales que el actual folklorismo realmente valora.

Las fiestas tradicionales de origen religioso constituyen un buen banco de recursos para el folklorismo, pero no son el único ejemplo del nuevo uso que nuestra sociedad hace de las manifestaciones de la religiosidad popular. A modo de colofón, permítaseme mencionar, aunque sólo sea de manera breve, el uso de los gozos por parte del folklorismo. Es bien conocida la gran difusión, dentro del ámbito geográfico de la antigua Corona de Aragón, que poseen los gozos. Desde finales del siglo XVI, estos himnos, dedicados a las más diversas advocaciones religiosas, se imprimen tradicionalmente en hojas sueltas, de manera que su interés etnográfico es amplio. Además de lo que de ellos se deduce en cuanto a la práctica y actitudes relacionados con la religiosidad popular, deben ser tenidos en cuenta desde el punto de vista del texto, de la melodía y de la hoja impresa. En la actualidad, se siguen editando gozos según los moldes tradicionales, pero ya no tan sólo por razones religiosas, sino también porque han adquirido valor folklórico. En Cataluña, en las fiestas de tipo popular, no es ningún hecho insólito que, en tenderetes improvisados, se hallen a la venta facsímiles de antiguos gozos o incluso nuevas ediciones que, además de dar un cariz tradicional servirán de "Souvenir" al visitante. En estos casos, no deben ser considerados, evidentemente, como expresión de la religiosidad popular, sino que su uso tiene mucho más que ver con el deseo de mantener una tradición conscientemente manipulada e instrumentalizada. Desde el punto de vista formal, semántico y funcional, estas nuevas ediciones de gozos siguen las leyes básicas que caracterizan toda producción folklorística, sea del género que sea. La nueva función de estos himnos impresos hace que éstos, formalmente, se adapten a las exigencias y necesidades propias del folklorismo. A menudo se elimina de la hoja impresa el oremus, un elemento imprescindible de los gozos tradicionales pero que en su calidad de "souvenir" puede parecer innecesario. Por otra parte, muy frecuentemente, se incluyen en la parte posterior de la

27 En los fuegos de Santa Catalina que se hacían en el monasterio mallorquín de Cura, por ejemplo, los campesinos prestaban atención a la altura que podían llegar a tener las llamas, puesto que se decía que sería la misma que conseguirian los sembrados. Cfr. Antoni Galmes RIERA, Cultura popular mallorquina (Palma de Mallorca, 1982), p. 145. 
hoja datos de tipo histórico o turístico, relacionados con la población en cuestión que, de hecho, nada tienen que ver con los gozos estrictos. El contenido devocional que podían poseer antiguamente las hojas impresas de los gozos, como es el caso de cualquier estampa religiosa, desaparece desbancado por su nueva significación como producto representante de una tradición étnicar. Si antes se vendían sobre todo en las iglesias y ermitas, y se distribuían especialmente en la festividad del santo al cual estaban dedicados, ahora, estos impresos pueden ocupar un puesto más en la vitrina de "souvenirs. y se expenden según los criterios del «marketing local.

Actualmente, en el ámbito de las manifestaciones tradicionales de la religiosidad popular, resultaría totalmente incoherente limitar nuestro estudio a los aspectos estrictamente credenciales, tal como quizá se hubiese pretendido hacer antes de la aparición en nuestra sociedad del componente ideacional del folklorismo. Toda manifestación puntual de la cultura popular está constituida por una compleja imbricación de formas, significaciones y funciones y desde que la tradición, entendida como ‘folklore", pasó a engrosar el cuadro de valores propios de nuestra sociedad, cualquier expresión de esta cultura cargada de atavismos no puede dejar de ser también interpretada teniendo en cuenta la base ideacional del folklorismo. Sin ella no podría llegar a entenderse la relevancia social que poseen muchas de las actuales recreaciones de nuestra tradición.

JOSEP MARTI I PÉREZ

C.S.I.C., Barcelona

Difícilmente podriamos llegar en la actualidad a comprender las diferentes manifestaciones de la cultura tradicional sin tener en cuenta las implicaciones formales, semánticas y funcionales del folklorismo, entendiendo este último término como todo aquello que hace relación al uso que se hace del folklore, una vez la sociedad ha devenido consciente de su existencia. Dado que el mundo de la vida tradicional está profusamente impregnado de formas y contenidos procedentes del ámbito religioso, las manifestaciones de la religiosidad popular también son objeto de la práctica folklorística de nuestra sociedad. El análisis de esta problemática constituye el eje central del presente artículo.

At present it is hard to understand the different expressions of traditional culture if we don't take into account the formal semantic and functional aspects of folklorism, i.e. the use of folklore after the society has become aware of its existence. The world of traditional life is widely impregnated of forms and contents from the religious context and thereby this field is also object of the folklorist practice of our society. The analysis of these questions constitutes the essential part of this article. 